\title{
Full Recovery from Symptomatic Lassa fever with Overt Bleeding without Ribavirin Therapy: A Case Report
}

\author{
Chukwu, Sunday Kyrian ${ }^{1,2^{*}}$, Unigwe, Sonny Uche ${ }^{1,2}$, Iroezindu, Michael Onyebuchi ${ }^{2}$, Mmerem, \\ Juliet Ijeoma $^{2,3}$, Umenzekwe, Chukwudi ${ }^{2,4}$ and Obeagu, Emmnuel Ifeanyi ${ }^{5}$ \\ ${ }^{\mathrm{T}}$ Department of Internal Medicine, Alex Ekwueme Federal University Teaching Hospital Abakaliki (AEFUTHA), Ebonyi \\ State \\ ${ }^{2}$ Department of Medicine, University of Nigeria Teaching Hospital Ituku/Ozalla Enugu, Enugu State \\ ${ }^{3}$ Department of Internal Medicine, Federal Medical Centre Owerri, Imo State Nigeria \\ ${ }^{4}$ Department of Internal Medicine, Nnamdi Azikiwe University Teaching Hospital Nnewi, Anambra State \\ ${ }^{5}$ Department of Medical Laboratory Science, Imo State University, Owerri, Nigeria
}

\section{*Corresponding Author}

Chukwu, Sunday Kyrian

\author{
Article History \\ Received: 28.07.2020 \\ Accepted: 05.08 .2020 \\ Published: 13.08.2020
}

\begin{abstract}
Lassa fever (LF) is a viral haemorrhagic fever (VHF) endemic in West Africa including parts of Nigeria. Ribavirin has been shown to have therapeutic benefits especially if commenced within six days of the symptoms. After seven days, patient with LF tend to progress to clinical stage 3 characterized by multiple complications including bleeding with poor prognosis. We report a case of LF with clinical stage 3 symptoms, which made full recovery without ribavirin therapy. This is a case report of confirmed LF case managed at University of Nigeria Teaching Hospital Ituku/Ozalla. LF was confirmed using RT-PCR of venous blood sample. Other investigations performed include liver function test (LFT), serum electrolyte, urea and creatinine (SEUC), full blood count (FBC), urinalysis. A 24 year old male was referred from private hospital with two weeks history of fever associated with myalgia, anorexia and bleeding per rectum significant enough to require blood transfusion. A preliminary diagnosis of sepsis with bleeding diathesis was made. Although the FBC and SEUC findings were within normal limits, findings of elevated transaminases (AST > ALT), haematuria and proteinuria heightened the clinical suspicion of LF. He was managed conservatively with intravenous fluids, antipyretics, antibiotics, blood transfusion and nutritional support. Empirical ribavirin therapy was not possible due to unavailability of the drug. After eight days, his symptoms resolved and no new complications were observed. He was counseled and discharged home on request. Lassa virus RT-PCR result received after his discharged turned out positive. Contact tracing was carried out but none of his primary contacts developed symptoms of Lassa virus infection. He has remained stable. Individuals suffering from LF and its complications could potentially experience favourable prognosis following optimal conservative management if ribavirin is unavailable. This information is useful for management of LF in resource-limited settings.
\end{abstract}

Keywords: Lassa fever, bleeding, recovery, ribavirin, conservative management.

\section{INTRODUCTION}

Lassa fever (LF) is a viral haemorrhagic fever (VHF) endemic in West Africa including Nigeria [1]. It is estimated that 300 to 500 thousand cases of Lassa virus infection with 5,000-10,000 occur annually across West Africa [2]. The incubation period is 3 to 21 days [3, 4]. The onset of the LF illness typically comprises non-specific symptoms and signs difficult to distinguish from other more common febrile illnesses [5,6]. Ribavirin has been shown to have therapeutic benefits especially if commenced within six days of the symptom onset [7]. After seven days, patients with LF tend to progress to clinical stage 3 characterized by multiple complications including bleeding with poor prognosis [1].

Copyright @ 2020: This is an open-access article distributed under the terms of the Creative Commons Attribution license which permits unrestricted use, distribution, and reproduction in any medium for non commercial use (NonCommercial, or CC-BY-NC) provided the original author and source are credited. 
The paper was written to report a case of LF with clinical stage 3 symptoms, which made full recovery without ribavirin therapy.

\section{MeTHODS}

This is a case report of a confirmed LF case managed at University of Nigeria Teaching Hospital (UNTH) Ituku/Ozalla. The UNTH is the largest tertiary institution in South-East Nigeria, with a purpose-built 5-bed capacity isolation facility managed by the Infectious Diseases Unit of Department of Medicine. LF was confirmed using Real time polymerase chain reaction (RT-PCR) of venous blood sample. Other Laboratory investigations performed include;

- $\quad$ Liver function test (LFT)

- Serum electrolyte, urea and creatinine (SEUC)

- Full blood count (FBC)

- $\quad$ Prothrombin time (PT)/International normalized ratio (INR)

- No statistical analysis was performed for this case report

\section{Findings: Clinical Presentation}

A 24 year old male medical laboratory scientist was referred from a private hospital with two weeks history of high-grade intermittent fever associated with:

- Myalgia

- Anorexia

- Bleeding per rectum significant enough to require blood transfusion

- There was no history of bleeding from any other orifice

- Review of systems was not remarkable

- No History of contact with anyone with similar symptoms.

- Further probing on the nature of specimens he had handled at work in the 3-4 weeks prior to symptom onset was not revealing.

- Prior to referral, he had received treatment including anti-malarials and antibiotics without sustained clinical improvement.

\section{Physical Examination Findings}

Physical examination revealed the following:

- Temperature of $38.4^{\circ} \mathrm{C}$, pale, dehydrated, pulse rate of $110 \mathrm{~b} / \mathrm{m}$, blood pressure of $120 / 70 \mathrm{mmHg}$, respiratory rate $=28 \mathrm{c} / \mathrm{m}$.

- Other examination findings are essentially normal except for stool that contained blood.

- A preliminary diagnosis of sepsis with bleeding diathesis was made.

- VHF was entertained as a possible differential

\section{LABORATORY RESULTS}

- $\quad$ FBC: $\mathrm{Hb}=7 \mathrm{~g} / \mathrm{dl} ; \mathrm{T}-\mathrm{WBC}=8.71 \times 10^{\wedge} 9 / \mathrm{L} ;$ Diff-WBC: $\mathrm{N}=68.2 \% \% ; \mathrm{L}=20.8 \%$;

- $\quad$ SEUC: $\mathrm{Na}=138 \mathrm{Mmol} / \mathrm{L} ; \mathrm{K}=4.5 ; \mathrm{Cl}=102 ; \mathrm{HCO}=28 ; \mathrm{Urea}=2.78 ; \mathrm{Cr}=76$ micromoles $/ \mathrm{L}$;

- $\quad$ LFT: $\mathrm{T}-\mathrm{Bil}=0.5 \mathrm{mg} / \mathrm{dl} ; \mathrm{C}-\mathrm{Bil}=0.3 \mathrm{mg} / \mathrm{dl} ; \mathrm{ALT}=35 \mathrm{iu} / \mathrm{L} ; \mathrm{AST}=72 \mathrm{iu} / \mathrm{L} ; \mathrm{ALP}=84 \mathrm{iu} / \mathrm{L}$;

- INR: 1.59

- Urinalysis: protein $2+$, blood 3+

- $\quad$ Findings of elevated transaminases (AST>ALT), deranged INR, haematuria and proteinuria heightened the clinical suspicion of VHF.

\section{Treatment}

He was managed conservatively in the isolation facility of the ID unit with:

- Intravenous fluids

- Antipyretics

- Antibiotics

- Blood transfusion

- Nutritional support

Empirical ribavirin therapy was not possible due to unavailability of the drug. After eight days, his symptoms resolved and no new complications were observed. He was counseled and discharged home on request. Lassa virus RTPCR result received after his discharge turned out positive. The PCR was done AEFUTHA. 


\section{Further Management}

Contact tracing was carried out but none of his primary contacts developed symptoms of Lassa virus infection. He was followed up and he has remained stable. He received extensive counselling regarding sexual intercourse with his partner and other public health measures

\section{DISCUSSION}

Recovery from Lassa fever without ribavirin therapy is perceived to be rare. Only few cases have been documented to have recovered without ribavirin therapy [8]. To the best of my knowledge, there is no confirmed Lassa fever case with bleeding diathesis that recovered without ribavirin therapy in the available literature. At presentation, our patient's clinical features could support sepsis but the presence of rectal bleeding and poor response to antimicrobials raised suspicion of possible VHF. The surrogate markers identified in the available Lab results strengthened the clinical suspicion of LF. In the absence of ribavirin therapy we were constrained to rely exclusively on good supportive care. Bleeding diathesis is a poor prognostic factor in Lassa virus infection [9], however, our patient had good prognosis having recovered with good supportive care. Beyond supportive care, we probably think that our patient might have mounted a strong host immune response that helped to contain the infection. The role of host immunity in the outcome of Lassa virus infection has been previously documented [10]. The Lassa virus RT-PCR used to confirm the diagnosis is the gold standard diagnosis [11]. It has a high sensitivity and specificity. Our report suggests that in the absence of ribavirin, optimal supportive care increases the chances of a favourable prognosis in LF.

\section{Lessons Learnt}

High index of suspicion is required to make diagnosis of Lassa fever in an area where it is not endemic. Recovery from Lassa fever even when there is overt bleeding may be achieved with proper conservative management in absence of ribavirin.

\section{Challenges encountered}

There was no obvious identifiable risk factor for Lassa virus infection in the patient. Unavailability of ribavirin. Patient and relatives insisting on going home despite adequate counseling not to go.

\section{CONCLUSION}

Individuals suffering from LF and its complications could potentially experience favourable prognosis following optimal supportive management in the absence of ribavirin therapy. This information is useful for management of LF in resource-limited settings. Further studies are needed to explore the immunological basis and other factors that promote good prognosis in LF without drug-specific treatment.

\section{REFERENCES}

1. Denue, B. A., Stephen, M., \& Dauvoux, I. (2017). The unending threat of Lassa fever in Nigeria, what can be done; what should be done. Port Harcourt Medical Journal, 11(3), 113.

2. Ogbu E A. (2019). Lassa fever in West African sub-region: An overview | O Ogbu | Request PDF [Internet]. [cited 2019 Aug 23]. Available from: https://www.researchgate.net/publication/6429499_Lassa_fever_in_West_African_sub-region_An_overview

3. Mofolorunsho, K. C. (2016). Outbreak of lassa fever in Nigeria: measures for prevention and control. Pan African Medical Journal, 23(1).

4. World health organization.(2019). Lassa fever [Internet]. [cited 2019 Aug 21]. Available from: https://www.who.int/news-room/fact-sheets/detail/lassa-fever

5. Bond, N., Schieffelin, J. S., Moses, L. M., Bennett, A. J., \& Bausch, D. G. (2013). A historical look at the first reported cases of Lassa fever: IgG antibodies 40 years after acute infection. The American journal of tropical medicine and hygiene, 88(2), 241-244.

6. WHO | Lassa fever - Nigeria. (2018). WHO [Internet]. 2018 [cited 2019 Jul 28]; Available from: https://www.who.int/csr/don/01-march-2018-lassa-fever-nigeria/en/

7. Ihekweazu, C. (2019). National guidelines for lassa fever case management 1 | [Internet]. [cited 2019 Jul 28 ]. Available from: https://ncdc.gov.ng/themes/common/docs/protocols/92_1547068532.pdf

8. Ajayi, N. A., Ukwaja, K. N., Ifebunandu, N. A., Nnabu, R., Onwe, F. I., \& Asogun, D. A. (2014). Lassa fever-full recovery without ribavarin treatment: a case report. African Health Sciences, 14(4), 1074-1077.

9. Warner, B. M., Safronetz, D., \& Stein, D. R. (2018). Current research for a vaccine against Lassa hemorrhagic fever virus. Drug design, development and therapy, 12, 2519.

10. Mazzola, L.T., Kelly-Cirino, C. (2019). Diagnostics for Lassa fever virus: a genetically diverse pathogen found in low-resource settings. BMJ Glob Heal [Internet]. 2019 Feb 7 [cited 2019 Aug 20];4(Suppl 2):e001116. Available from: http://gh.bmj.com/lookup/doi/10.1136/bmjgh-2018-001116 
11. Raabe, V., Koehler, J. (2019). Laboratory Diagnosis of Lassa Fever. J Clin Microbiol [Internet]. 2017 Jun 1 [cited 2019 Jul 28];55(6):1629-37. Available from: http://www.ncbi.nlm.nih.gov/pubmed/28404674

12. Yun, N.E., Walker, D.H. (2019). Pathogenesis of Lassa fever. Viruses [Internet]. 2012 Oct 9 [cited 2019 Aug 19];4(10):2031-48. Available from: http://www.ncbi.nlm.nih.gov/pubmed/23202452 